\title{
Impact of water fluoridation on dental caries decline across racial and income subgroups of Brazilian adolescents.
}

Water Fluoridation, inequalities and caries decline

Rafael Aiello Bomfim ${ }^{1,2}$

Paulo Frazão ${ }^{2}$

1-Department of Community Health, Federal University of Mato Grosso do Sul (UFMS), Campo Grande, Brazil

2-Public Health School, University of São Paulo, São Paulo, Brazil

*Corresponding author:

Rafael Aiello Bomfim - Professor

Bomfim RA Professor, School of Dentistry, Department of Community Health, Federal University of Mato Grosso do Sul (UFMS), Campo Grande, Brazil and Pos Doc researcher Public Health School, São Paulo, Brazil.

E-mail: aiello.rafael@gmail.com

Tel +55 67999260103

Number of Tables: 3

Number of Figures: 0

Supplemental online: 1

Word count: 2618

Keywords: Caries detection, Epidemiology, Fluoride, Public dental health

\section{Acknowledgements}

The author $(\mathrm{RAB})$ received a junior postdoc scholarship from CNPq Brazil process 153623/2018-7. This study was financed in part by the Fundação Universidade Federal 
de Mato Grosso do Sul - UFMS/MEC - Brazil. The author (PF) is a researcher of the Brazilian Council for Technological and Scientific Development (CNPq 305132/2019-9).

\section{Statement of Ethics}

This investigation complies with the guidelines for human studies and should include evidence that the research was conducted ethically following the World Medical Association Declaration of Helsinki. All subjects have given their written informed consent, and that the institute's committee approved the study protocol on human research. Ethical approval for the SB Brazil 2010 was granted by the Ethics Health Commission (CNS), Resolution (CNS) 15498, on July 1, 2010, and in 2003 resolution CNS 1.356, process $25.000 .009 .632 / 00-51$ on July 21,2000 . All participants provided their informed consent.

\section{Conflict of Interest Statement}

The authors have no conflicts of interest to declare.

\section{Funding Sources}

CNPq Brazil process 153623/2018-7. This study was financed in part by the Fundação Universidade Federal de Mato Grosso do Sul - UFMS/MEC - Brazil.

\section{Author Contributions}

Author $1 \mathrm{RAB}$ : Contributed to conception, design, data interpretation, performed all statistical analyses, drafted and critically revised the manuscript

Author 2 PF: Contributed to conception, design, data interpretation, drafted and critically revised the manuscript 
All authors gave their final approval and agreed to be accountable for all aspects of the work.

More information could be seen at:

SBBrasil 2003:

https://bvsms.saude.gov.br/bvs/publicacoes/condicoes_saude_bucal.pdf

SBBrasil 2010:

https://bvsms.saude.gov.br/bvs/publicacoes/pesquisa_nacional_saude_bucal_sbbrasil_2

010.pdf 


\section{Impact of water fluoridation on dental caries decline across racial and income subgroups of Brazilian adolescents.}

\section{Abstract}

Objective. To assess the impact of community water fluoridation (CWF) on differences in dental caries decline across racial and socioeconomic subgroups of Brazilian adolescents. Methods. Two nationwide Brazilian population-based oral health surveys were used (SBBrazil 2003-2010). Seven thousand one hundred ninety-eight adolescents from 15 to 19 years old living in fifty cities investigated in both surveys were included. Mean values of untreated decayed teeth (DT) according to racial (Whites versus Browns/Blacks) and socioeconomic subgroups (at or above one minimum wage per capita versus under) were analyzed. Difference-in-Differences negative binomial regressions were adjusted by schooling, age, and sex. Decayed, missing, and filled teeth (DMFT) and decayed teeth prevalence were used for sensitivity analysis. Results. The adjusted difference of reduction in DT was similar for socioeconomic subgroups $[\beta=-$ $0.05(-0.45,0.35)]$ and favoured but not to a significant degree the Whites $[\beta=-0.34(-$ 0.74, 0.04)] compared to Brown/Blacks in the fluoridated area. Significant reduction differences were observed in decayed teeth favouring the higher socioeconomic subgroup $[\beta=-0.26(-0.53,-0.01)]$ and the Whites $[\beta=-0.40(-0.69,-0.11)]$ in relation to their counterparts in the non-fluoridated area. Sensitivity analysis confirmed the findings. Conclusion. A similar reduction in DT across income subgroups suggests the beneficial effect of CWF to tackle income inequalities in dental caries within a 7-year timeframe.

Keywords: Water fluoridation, racial inequalities, socioeconomic inequalities, dental caries, oral health, public health 


\section{Introduction}

Dental caries is one of the most prevalent diseases globally. Untreated dental caries affects $35 \%$ of the worldwide population (2.4 billion people), with a greater impact on socioeconomically disadvantaged and vulnerable ${ }^{1}$.

The preventive effects of conjoint exposure (e.g., use of fluoride toothpaste in a fluoridated area) are additive and lower than the sum of each one's effect ${ }^{2}$. Moreover, Community Water Fluoridation (CWF) is associated with reduced dental ambulatory sensitive hospitalizations ${ }^{3}$, and its cessation increased decayed primary teeth ${ }^{4}$.

Although the information on the impact of water fluoridation on dental caries inequalities is insufficient ${ }^{5}$, some studies have shown that CWF has the potential to reduce race- and income-related inequalities ${ }^{6-8}$. For example, in Brazil, which has the world's largest population of African descent outside of the native continent, a study showed that CWF was associated with reduced ethnic inequalities in dental caries in deprived settings ${ }^{9}$.

The use of fluoride is a breakthrough in public health, and the 6017 resolution from World Health Assembly confirms the relevance of CWF policy for promoting oral health ${ }^{10}$. More than a political issue, CWF is an ethical issue ${ }^{11}$. Communities that have ceased fluoridation showed increased values of dental caries in children ${ }^{4,12-13}$. Australian children from 9 to 14 years old and $100 \%$ of lifetime exposure to fluoridated water had significantly less dental caries than those with lower exposure ${ }^{14}$. Comparing USA counties with distinct levels of water fluoridation coverage ( $\geq 75 \%$ versus $<75 \%$ ), researchers found a difference of $12 \%$ in dental caries experience in children and adolescents aged 6 to 17 years old ${ }^{15}$.

A randomized controlled trial is a study design essential for assessing clinical interventions; however, it is challenging to manage for evaluating the efficacy of 
population-based public policies like water fluoridation. Therefore, other methods specifically designed for causal inference in observational data have been proposed for impact assessment ${ }^{16-17}$. In Brazil, the fluoridation of public water supplies is mandatory since 1974, according to Federal Law 6,050. However, it is estimated that $40 \%$ of the Brazilian cities are not provided by this beneficial public health policy ${ }^{18}$. Dental caries has been declining, and income inequalities persist in Brazil ${ }^{19}$. To the author's knowledge, no study compared decline differences across income and racial subgroups in two timepoints according to fluoridated and non-fluoridated areas utilizing a Difference-inDifference approach ${ }^{17}$. Although this design permits the investigation of a potential association between policy implementation and the measured outcome, the main focus was to verify whether the decline differed across racial and income subgroups.

The aim was to assess the impact of community water fluoridation on differences in dental caries decline across racial and socioeconomic subgroups of Brazilian adolescents between 2003 and 2010 in the context of widespread use of fluoride toothpaste.

\section{Methods}

Data came from the latest two nationwide population-based oral health surveys in $2003^{20}$ and $2010^{21}$ (Brazilian Oral Health Survey - SBBrasil-2003 and PNSB-2010). In 2003, the survey was conducted in 250 municipalities and in 2010 in 177 municipalities. Probability cluster sampling was used for selecting children, adolescents, adults and elders. Only individuals from 15 to 19 years old living in cities investigated in both surveys were included in the analysis.

Both surveys' interviews and clinical examinations followed the same criteria recommended by $\mathrm{WHO}^{22}$ for dental caries measuring and were carried out in respondents' homes by teams consisting of a general dentist and an assistant. Handbooks were 
particularly elaborated to guide the procedures of sampling and data collection at each survey. Depending on the field characteristics, two to five dental examiners were selected and underwent between 24 and 32 hours of training and calibration in each municipality alone or in group of two or three municipalities. Kappa values above 0.65 were considered acceptable in both surveys ${ }^{20,21}$. Examiners with Kappa values above 0.65 were approved for data collection.

Ethical approvals for 2003 and 2010 oral health surveys were granted by the Research Ethics Commission of Brazilian Health Council respectively on July 21st, 2000 (Resolution CNS 1.356), and on July 1st, 2010 (Resolution CNS 15498). All participants provided their informed consent.

The outcome was the mean values of untreated decayed teeth (DT), defined as a count variable that estimates the participant's current disease severity. According to WHO criteria, DT was recorded where a lesion in the pit and fissure or on a smooth tooth surface had an unmistakable cavity, undermined enamel, or a detectably softened floor or wall; or where a temporary restoration (except glass ionomer) was present ${ }^{22}$. The CPI probe was used to confirm caries' visual evidence on the occlusal, buccal, and lingual surfaces. We considered the tooth and not the surface as the unit parameter.

The investigated intervention was the provision of CWF. Fifty Brazilian cities were investigated both at 2003 and 2010 oral health surveys, and twenty-five of them provided CWF since at least 2000. They were grouped into two different strata, the non-fluoridated and fluoridated areas. Information on CWF was obtained from two different data sources, based on the information provided by water companies and municipal water surveillance ${ }^{18,23-24}$. 
The effect of CWF was assessed according to different categories of racial and income subpopulations. The racial variable was based on the respondent's self-assessment considering categories used by the Brazilian Institute for Geography and Statistics, based on skin colour. The categories included Whites, Asians, Browns (mixed ethnicity), Blacks, and Indigenous groups ${ }^{25}$. As proportions of adolescents belonging to Indigenous $(0.8 \%)$ and Asian (1\%) groups were very small in the two independent samples, they were not included in the final analysis. Income was measured using equivalised per capita monthly household income and dichotomized to distinguish between families living below the Brazilian minimum wage $(<1 \mathrm{MW})$ and those at or above minimum wage $(\geq 1 \mathrm{MW})^{26}$. In December 2003, the Brazilian minimum wage was BRL 240 (Brazilian Reais) or 83,33USD (US Dollars). In December 2010, the Brazilian minimum wage was BRL 510.00 (Brazilian Reais) or USD 301.70 (US Dollars). Covariates were age in years, sex (male; female), and schooling (under and at or above four years) related to the adolescents.

Descriptive analyses included cross-tabulations of the outcome for racial (Whites versus Browns/Blacks) and equalized income (under and at or above one MW) subgroups according to the CWF. Point estimates and 95\% confidence intervals interpreted the outcome mean values. Both areas are experiencing declining trends of dental caries ${ }^{17}$. There was no change in the drinking water status during the study period. As the focus was to investigate reduction differences across racial and income subgroups, the fact of CWF intervention to have begun at least three years before the baseline data did not undermine the analysis herein undertaken.

We regressed DiD stratified by CWF exposure. In the stratum of the CWF area, the association between the outcome and categories of racial subgroups (Browns/Blacks versus Whites) and socioeconomic subgroups (lower versus upper income), with an interaction term, i.e., the year, was investigated. The same was done in the stratum of 
non-fluoridated areas (control units). This analysis quantifies the reduction difference of the outcome between the years across racial and socioeconomic subgroups. Due to the overdispersion of the outcome values, coefficients across racial and socioeconomic subgroups were estimated using negative binomial regression. All analyses were adjusted by sex, age and schooling. Beta coefficient $(\beta)$ was interpreted as the mean reduction of a group compared to its reference group (R) with a 95\% confidence interval. Moreover, the percentage difference $(\% \mathrm{D})$ values resulting from the quotient between the $\beta$ coefficient and the baseline mean of the reference group (R) were also reported ${ }^{27}$.

Analyses were carried out using Stata Version 14.2 (College Station, TX, EUA). Sampling weights available in the database were employed. All analyses were based on complete cases (without missing values) in the independent samples. Analysis comparing the total sample with the analyzed samples showed no significant differences in any outcome or covariates. Sensitivity analysis stratifying DT's number as dichotomous (0without caries and $1-\mathrm{D} \geq 1$ ) and using DMFT were done (supplementary material). We used the Strobe Guidelines to report the results of the present investigation.

\section{Results}

Seven thousand one hundred ninety-eight adolescents comprised the analytical sample. Table 1 shows the distribution of the sample's characteristics as a whole. At both 2003 and 2010 , the $95 \%$ confidence intervals of the mean values of untreated decayed teeth were significantly higher in the non-fluoridated than fluoridated area, and mean decayed teeth was higher for the lower-income group. In addition, the mean value of DT was significantly higher for Browns/Blacks than Whites in 2010. 
Adolescents self-declared Browns/Blacks had higher DT value than their counterparts in the non-fluoridated area in 2010. Those living in families with income under one per capita minimum wage had a higher value in untreated dental caries in the non-fluoridated area at both years and in the fluoridated area in 2010 (Table 2).

Table 3 shows the crude and adjusted Difference-in-Differences analysis outputs in mean values of DT across income and racial subgroups according to exposure to CWF from 2003 to 2010. The crude and adjusted outputs showed significant differences only in the non-fluoridated area. Adolescents living in families included in the higher income group and those self-declared Whites had significant DT mean reductions, respectively, $12.4 \%$ and $14.8 \%$ than their counterparts. Contrarily, the differences were non-significant in the fluoridated area although more favourable for Whites $[\beta=-0.34(-0.74,0.04)]$ than Blacks/Browns. Supplement 1 showed an analysis of the missing values. Sensitivity analysis based on percentages of individuals with at least one untreated decayed tooth confirmed our findings (Supplement 2). While in the fluoridated area, the reduction in the proportion of people with at least one decayed tooth was similar for racial and socioeconomic groups, in the non-fluoridated area, the reduction was more prominent for wealthier and Whites.

\section{Discussion}

The exposure to water fluoridation showed no difference in DT reduction between income subgroups, suggesting favourable trends to health equity amongst Brazilian adolescents while in the non-fluoridated area favoured wealthier and Whites.

In both areas, we observed a reduction of mean decayed teeth. This declining trend has been observed worldwide due to the widespread use of fluorides ${ }^{2}$. Investigations showed 
that dental caries have also been reducing in the overall young Brazilian population, but these improvements have not been similar among socioeconomic groups ${ }^{19,28}$. However, these studies did not compare the changes according to exposure to CWF. Our findings showed similar decreases across socioeconomic subgroups in the mean values of DT in the fluoridated area, while the differences remained in the non-fluoridated area. In a study with Australian children, all inequality indexes indicated that caries experience was concentrated among lower-income groups and was lower in the fluoridated than in the non-fluoridated area $^{29}$.

Regarding racial subgroups, although the differences in DT reduction have been nonsignificant, they were as wide as those observed for income subgroups. Considering the rates of individuals with at least one untreated decayed tooth (Supply 2), the differences in reduction were compatible with similar values for both income and racial subgroups in the fluoridated area contrarily to the non-fluoridated area which reductions were higher for wealthier and Whites. As the income differences were estimated adjusting by racial groups and vice versa, this finding could mean that income differences are more amenable by CWF than racial differences, a hypothesis to be confirmed for further DiD analysis. Previous evidence comes from cross-sectional studies. One showed that CWF did not reduce racial inequalities significantly ${ }^{31}$, while the other observed no significant ethnic inequalities in deprived settings with $\mathrm{CWF}^{9}$.

Race has emerged to explain the persistence of health inequalities in some contexts ${ }^{32}$. The relative disadvantage that racial groups face in terms of oral health has been interpreted as stemming from structural or macro-level processes. This includes dental care, living in deprived neighborhoods, and restricted access to dental care and fluoridated piped water ${ }^{33}$. These inequalities persisted in the adjusted models for gender, schooling, income and age. In general, those from higher socioeconomic status (SES) know about 
the risks and have the resources-money, knowledge, power, prestige, and beneficial social connections - to engage in the prevention than treatment ${ }^{34}$. Our study demonstrated that even adjusting for schooling and income (an inherent part of SES), lower health gain for Browns/Blacks than Whites was observed in the non-fluoridated area. In other words, it means that race and SES are not overlapped. One possible explanation could be related to difficult access to fluoridated toothpaste by different racial groups ${ }^{35}$.

In the non-fluoridated area, the reduction of mean untreated decayed teeth was higher for wealthier than their counterparts. Decomposition analysis on dental caries experience among 9 to $14-y-o l d s$ Australian children showed that exposure to CWF explained one third of area-level income inequalities ${ }^{36}$. Other studies have shown the effect of CWF on reducing dental caries in the context of multiple sources of fluoride $5,8,14,15,37$. Do et al. (2018) found that income-related inequality in caries was lower in fluoridated than in non-fluoridated areas for Indigenous and non-Indigenous children. One study showed benefits associated with higher lifetime exposure to CWF even adjusting for socioeconomic conditions $^{14}$, and another showed potential benefits of CWF on income inequalities ${ }^{38}$, corroborating our findings.

Our study has some strengths and limitations. First, this Difference-in-Differences approach used data from two national epidemiological surveys that accurately reflected the country's characteristics as a whole. We utilized data from only 50 cities that participated in 2003 and 2010 surveys, so the cluster units (cities) were the same. Second, water fluoridation levels were determined using different data sources, thereby improving their reliability. Third, distinctly from other dental caries measurement tools, the selected outcome (mean untreated decayed teeth) measures the current disease severity that is an indicator less affected by differences in access to oral healthcare and by the dentist's decision to restore. The outcomes (mean untreated decayed teeth) across socioeconomic 
and racial subgroups according to exposure to CWF were compared during seven years. They showed the impact of CWF independently of other dental caries determinants affecting both the exposure and non-exposure group ${ }^{16}$. One limitation was that data on exposure to fluorides at the individual level were not available. In the DID approach, the baseline data is expected to be at the beginning of the intervention and in the current study's design, we are sure that the intervention began at least three years before, according to available official data from national sanitation research gathered at 2000. As the investigated intervention was measured in a defined age group, exposed and nonexposed to CWF during the group's lifetime, the difference between those times does not undermine the analysis. The ideal picture would be that all cities included in the fluoridated area had begun the public policy implementation simultaneously and at least ten years before so that effects could be observed at the permanent dentition of 15-19year-old adolescents. As this paper is the first reporting CWF's effect by a DiD analysis, further studies are needed to elucidate points not addressed herein. The complexity involved in racial classification in Brazil must also be highlighted ${ }^{9,39}$; however, it is the best data representing the Brazilian population of adolescents as a whole.

In conclusion, the similar reduction in decayed teeth across income subgroups suggests the beneficial effect of CWF to tackle income inequalities in dental caries within a 7-year timeframe.

\section{References}

1. Kassebaum NJ, Bernabé E, Dahiya M, Bhandari B, Murray CJ, Marcenes W. Global burden of untreated caries: a systematic review and metaregression. J Dent Res. 2015;94(5):6508.

2. Whelton HP, Spencer AJ, Do LG, Rugg-Gunn AJ. Fluoride Revolution and Dental Caries: Evolution of Policies for Global Use. J Dent Res. 2019;98(8):837-46.

3. Hobbs M WA, Jones P, Marek L, Tomintz M, Sharma K, McCarthy J , Mattingley B, Campbell M, Kingham S. Area-level deprivation, childhood dental ambulatory sensitive 
hospitalizations and community water fluoridation : evidence from New Zealand. Int J Epidemiol. 2020.

4. McLaren L, Patterson S, Thawer S, Faris P, McNeil D, Potestio ML, Shwart L. Exploring the short-term impact of community water fluoridation cessation on children's dental caries: a natural experiment in Alberta, Canada. Public Health. 2017 ;146:56-64.

5. Iheozor-Ejiofor Z, Worthington HV, Walsh T, O'Malley L, Clarkson JE, Macey R, et al. Water fluoridation for the prevention of dental caries. Cochrane Database Syst Rev. 2015(6):CD010856.

6. Jones C, Taylor G, Woods K, Whittle G, Evans D, Young P. Jarman underprivileged area scores, tooth decay and the effect of water fluoridation. Community Dent Health. 1997;14(3):15660 .

7. Riley JC, Lennon MA, Ellwood RP. The effect of water fluoridation and social inequalities on dental caries in 5-year-old children. Int J Epidemiol. 1999;28(2):300-5.

8. McDonagh MS, Whiting PF, Wilson PM, Sutton AJ, Chestnutt I, Cooper J, et al. Systematic review of water fluoridation. British Medical Journal. 2000;321(7265):855-9.

9. Bomfim RA, Watt RG, Tsakos G, Heilmann A, Frazão P. Does water fluoridation influence ethnic inequalities in caries in Brazilian children and adolescents? Community Dentistry and Oral Epidemiology, 2021. In press, doi: 10.1111/cdoe.12676.

10. Petersen PE, Ogawa H. Prevention of dental caries through the use of fluoride--the WHO approach. Community Dent Health. 2016;33(2):66-8.

11. Sisson KL. Theoretical explanations for social inequalities in oral health. Community Dent Oral Epidemiol. 2007;35(2):81-8.

12. Meyer J, Margaritis V, Mendelsohn A. Consequences of community water fluoridation cessation for Medicaid-eligible children and adolescents in Juneau, Alaska. Bmc Oral Health. 2018;18.

13. McLaren L, Singhal S. Does cessation of community water fluoridation lead to an increase in tooth decay? A systematic review of published studies. J Epidemiol Community Health. 2016;70(9):934-40.

14. Spencer AJ, Do LG, Ha DH. Contemporary evidence on the effectiveness of water fluoridation in the prevention of childhood caries. Community Dent Oral Epidemiol. 2018;46(4):407-15.

15. Slade GD, Grider WB, Maas WR, Sanders AE. Water Fluoridation and Dental Caries in U.S. Children and Adolescents. J Dent Res. 2018;97(10):1122-8.

16. Listl S, Jurges H, Watt RG. Causal inference from observational data. Community Dentistry and Oral Epidemiology. 2016;44(5):409-15.

17. Dimick JB, Ryan AM. Methods for Evaluating Changes in Health Care Policy The Difference-in-Differences Approach. Jama-Journal of the American Medical Association. 2014;312(22):2401-2.

18. Frazão P, Narvai PC. Cobertura e Vigilância da Fluoretação da água no Brasil: Municípios acima de 50 mil habitantes: Faculdade de Saúde Pública da USP; 2017.

19. Roncalli AG, Sheiham A, Tsakos G, Watt RG. Socially unequal improvements in dental caries levels in Brazilian adolescents between 2003 and 2010. Community Dent Oral Epidemiol. 2015;43(4):317-24.

20. Ministry of Health . Condições de Saúde Bucal da População Brasileira 2002-2003 Resultados Principais. 2004.

21. Roncalli AG, da Silva NN, Nascimento AC, Soares de Morais Freitas CH, Casotti E, Peres KG, et al. Relevant methodological issues from the SBBrasil 2010 Project for national health surveys. Cadernos De Saude Publica. 2012;28:S40-S57.

22. World Health Organization. Oral health surveys: basic methods - 4th edition. 1997.

23. IBGE. Brazilian Institute of Geography and Statistics. Pesquisa Nacional de Saneamento Básico 2000. Rio de Janeiro: IBGE; 2002. Available in: <http://www.ibge.gov.br/estatisticas/multidominio/meio-ambiente/9073-pesquisa-nacional-desaneamento-basico.html?edicao $=18098 \& \mathrm{t}=$ sobre $>$. Accessed in 14/02/2020. 
24. IBGE. Brazilian Institute of Geography and Statistics. Pesquisa Nacional de Saneamento Básico 2008. Rio de Janeiro: IBGE; 2010. Available in: <https://biblioteca.ibge.gov.br/index.php/biblioteca-catalogo?view=detalhes\&id=283636> Accessed 12/01/2020

25. IBGE. Brazilian Institute of Geography and Statistics. Censo Demográfico 2010. Rio de Janeiro: IBGE; 2011. <https://biblioteca.ibge.gov.br/visualizacao/periodicos/93/cd 2010 caracteristicas populacao d omicilios.pdf> Accessed 12/01/2020

26. Celeste RK, Bastos JL. Mid-point for open-ended income category and the effect of equivalence scales on the income-health relationship. Rev Saude Publica. 2013;47 Suppl 3:16871.

27. Basinga P, Gertler PJ, Binagwaho A, Soucat ALB, Sturdy J, Vermeersch CMJ. Effect on maternal and child health services in Rwanda of payment to primary health-care providers for performance: an impact evaluation. Lancet. 2011;377(9775):1421-8.

28. Roncalli AG, Sheiham A, Tsakos G, Araújo-Souza GC, Watt RG. Social Factors Associated with the Decline in Caries in Brazilian Children between 1996 and 2010. Caries Res. 2016;50(6):551-9.

29. Do LG, Ha DH, Roberts-Thomson KF, Jamieson L, Peres MA, Spencer AJ. Race- and Income-Related Inequalities in Oral Health in Australian Children by Fluoridation Status. JDR Clin Trans Res. 2018;3(2):170-9.

30. Vettore MV, Moysés SJ, Sardinha LM, Iser BP. [Socioeconomic status, toothbrushing frequency, and health-related behaviors in adolescents: an analysis using the PeNSE database]. Cad Saude Publica. 2012;28 Suppl:s101-13.

31. Schluter PJ, Lee M. Water fluoridation and ethnic inequities in dental caries profiles of New Zealand children aged 5 and 12-13 years: analysis of national cross-sectional registry databases for the decade 2004-2013. Bmc Oral Health. 2016;16.

32. Williams DR, Lawrence JA, Davis BA, Vu C. Understanding how discrimination can affect health. Health Services Research. 2019;54:1374-88.

33. Bastos JL, Celeste RK, Paradies YC. Racial Inequalities in Oral Health. J Dent Res. 2018;97(8):878-86.

34. Phelan JC LB. Is Racism a Fundamental Cause of Inequalities in Health? Annu Rev Social. 2015;41:311-30.

35. Chen CC, Chiou SJ, Ting CC, Lin YC, Hsu CC, Chen FL, et al. Immigrant-native differences in caries-related knowledge, attitude, and oral health behaviors: a cross-sectional study in Taiwan. BMC Oral Health. 2014;14:3.

36. Peres MA, Ju X, Mittinty M, Spencer AJ, Do LG. Modifiable Factors Explain Socioeconomic Inequalities in Children's Dental Caries. J Dent Res. 2019;98(11):1211-8.

37. Aguiar VR, Pattussi MP, Celeste RK. The role of municipal public policies in oral health socioeconomic inequalities in Brazil: A multilevel study. Community Dentistry and Oral Epidemiology. 2018;46(3):245-50.

38. Sanders AE, Grider WB, Maas WR, Curiel JA, Slade GD. Association Between Water Fluoridation and Income-Related Dental Caries of US Children and Adolescents. JAMA Pediatr. 2019;173(3):288-90.

39. Lima-Costa MF, Rodrigues LC, Barreto ML, Gouveia M, Horta BL, Mambrini J, et al. Genomic ancestry and ethnoracial self-classification based on 5,871 community-dwelling Brazilians (The Epigen Initiative). Scientific Reports. 2015;5. 


\section{Tables}

Table 1. Descriptive characteristics and weighted means of DT of Brazilian adolescents $(n=7198)$

\begin{tabular}{|c|c|c|c|}
\hline \multirow{2}{*}{ Individual variables } & \multirow{2}{*}{$n=7198$} & \multirow{2}{*}{$\%(95 \% \mathrm{CI})$} & \multirow{3}{*}{$\frac{\text { DT }}{\text { mean }(95 \% \mathrm{CI})}$} \\
\hline & & & \\
\hline \multicolumn{3}{|l|}{ Ethnic Group $2003(n=3178)$} & \\
\hline Whites & 1254 & $41.5(36.7-46.7)$ & $1.94(1.50-2.37)$ \\
\hline Browns+Blacks & 1924 & $58.5(53.6-63.3)$ & $2.23(1.96-2.50)$ \\
\hline \multicolumn{4}{|l|}{ Ethnic Group $2010(n=4020)$} \\
\hline Whites & 1653 & $43.0(40.5-45.6)$ & $1.24(1.04-1.44)$ \\
\hline Browns+Blacks & 2367 & $57.0(54.4-59.5)$ & $2.04(1.86-2.23)$ \\
\hline \multicolumn{4}{|l|}{ Per capita Income 2003} \\
\hline under minimum wage & 1641 & $48.6(43.7-53.4)$ & $2.57(2.19-2.94)$ \\
\hline At and above minimum wage & 1537 & $51.4(46.5-56.3)$ & $1.67(1.41-1.93)$ \\
\hline \multicolumn{4}{|l|}{ Per capita Income 2010} \\
\hline under minimum wage & 2158 & $54.2(51.6-56.7)$ & $2.08(1.88-2.29)$ \\
\hline At and above minimum wage & 1862 & $45.8(43.3-48.4)$ & $1.24(1.08-1.41)$ \\
\hline \multicolumn{4}{|l|}{ Fluoridation 2003} \\
\hline No & 1596 & $27.5(24.5-30.6)$ & $2.83(2.60-3.07)$ \\
\hline Yes & 1582 & $72.5(69.4-75.5)$ & $1.83(1.52-2.14)$ \\
\hline \multicolumn{4}{|l|}{ Fluoridation 2010} \\
\hline No & 1770 & $26.7(24.8-28.8)$ & $2.39(2.17-2.62)$ \\
\hline Yes & 2250 & $73.3(71.2-75.2)$ & $1.44(1.28-1.61)$ \\
\hline
\end{tabular}


Table 2. Decayed teeth weighted means of Brazilian adolescents, according to Fluoridation contexts $(n=7198)$

DT

DT

Individual variables

n

Ethnic Group 2003

Whites

Pardos+Blacks

Ethnic Group 2010

Whites

Pardos+Blacks

Per capita Income(equivalized)

2003

under minimum wage

above minimum wage

Per capita Income(equivalized)

2010

under minimum wage

above minimum wage
1596

422

1174

1770

573

1197

1596

937

659

1770

1019

751
Non-Fluoridated

$2.47(2.09-2.85)$

$2.98(2.69-3.27)$

$1.51(1.19-1.84)$

$2.85(2.57-3.13)$

$3.11(2.81-3.41)$

$2.41(2.20-2.80)$

2.96 (2.64-3.28)

1.69 (1.41-1.98) n

1582

832

750

2250

1080

1170

1582

704

878

2250

1139

1111
Fluoridated

$1.81(1.29-2.35)$

$1.85(1.49-2.21)$

1.17 (0.96-1.53)

1.68 (1.45-1.93)

$2.28(1.73-2.85)$

1.47 (1.17-1.79)

1.75 (1.50-2.01)

1.09 (0.89-1.28) 
Table 3. The Difference-in-Differences analysis in average values of number of DT amongst Brazilian adolescents and stratified by exposure to CWF ( $\mathrm{n}=7198)$

Mean Decayed Teeth Stratified by exposure to CWF

Non-Fluoridation Areas

\begin{tabular}{|c|c|c|c|c|c|c|c|c|c|}
\hline Socioeconomic groups & $\mathbf{n}$ & $\begin{array}{c}\text { Mean } \\
2003\end{array}$ & $\mathbf{n}$ & $\begin{array}{c}\text { Mean } \\
2010\end{array}$ & $\begin{array}{l}\text { Diff-in- } \\
\operatorname{Diff}^{2}(\beta)\end{array}$ & $\beta^{\mathrm{a}}(95 \% \mathrm{Cl})$ & $\begin{array}{l}\text { Diff-in- } \\
\operatorname{Diff}^{b}(\beta)\end{array}$ & $\beta^{b}(95 \% \mathrm{Cl})$ & $\% \mathrm{D}$ \\
\hline $\begin{array}{r}\text { under } 1 \mathrm{MW} \\
(\mathrm{R}) \text { above } 1 \mathrm{MW}\end{array}$ & $\begin{array}{l}937 \\
659\end{array}$ & $\begin{array}{l}3.11 \\
2.41\end{array}$ & $\begin{array}{c}1019 \\
751\end{array}$ & $\begin{array}{l}2.96 \\
1.69\end{array}$ & -0.30 & & -0.26 & $-0.53 ;-0.01$ & $-12.45 \%$ \\
\hline \multicolumn{10}{|l|}{ Racial groups } \\
\hline $\begin{array}{r}\text { Browns+Blacks } \\
\text { (R) Whites }\end{array}$ & $\begin{array}{c}1174 \\
422\end{array}$ & $\begin{array}{l}2.98 \\
2.47\end{array}$ & $\begin{array}{c}1197 \\
573\end{array}$ & $\begin{array}{l}2.85 \\
1.51\end{array}$ & -0.44 & $-0.74 ;-0.14$ & -0.40 & $-0.69 ;-0.11$ & $-14.77 \%$ \\
\hline Fluoridation Areas & & & & & & & & & \\
\hline
\end{tabular}

Socioeconomic groups

\begin{tabular}{|c|c|c|c|c|c|c|c|c|c|}
\hline under $1 \mathrm{MW}$ & 704 & 2.28 & 1139 & 1.75 & & $-0,43 ;+0.35$ & $-0,05$ & $-0.45 ;+0.35$ & $-2.72 \%$ \\
\hline (R) above $1 \mathrm{MW}$ & 878 & 1.47 & 1111 & 1.09 & & $0,0,0.00$ & $-0,0 J$ & $-0.40,70.05$ & 1210 \\
\hline Browns+Blacks & 750 & 1.85 & 1170 & 1.68 & \multirow{2}{*}{-0.34} & \multirow{2}{*}{$-0.77 ;+0.07$} & \multirow{2}{*}{-0.34} & \multirow{2}{*}{$-0.74 ;+0.04$} & \\
\hline (R) Whites & 832 & 1.81 & 1080 & 1.17 & & & & & -18.38 \\
\hline
\end{tabular}

$\beta$ - Crude coefficient; \%D - Percentage of Difference ( coefficient $\beta$ / baseline mean of reference (R) group) - MW - Per capita minimum-wage. DT - decayed teeth;

$\beta^{\mathrm{a}}$ - unadjusted $\beta^{\mathrm{b}}$ - adjusted for schooling, age, sex, income (if analyzing racial groups) and racial groups (if analyzing income) 


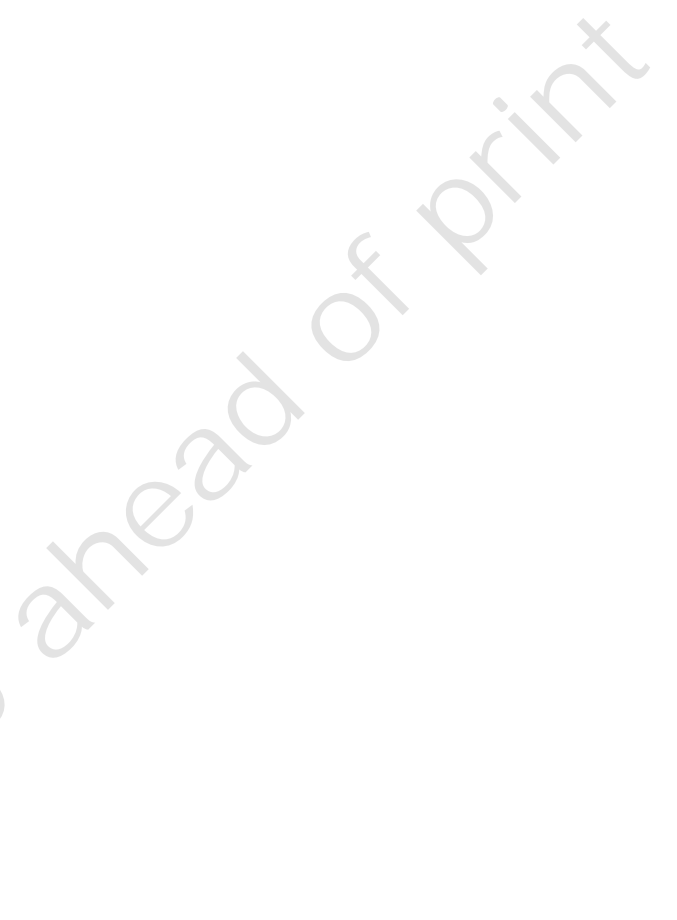

